\title{
Discrete Element Simulation of Bending Deformation of Geogrid-Reinforced Macadam Base
}

\author{
Hongjun JING*, Mingjie GOU, Lichen SONG
}

\begin{abstract}
The pavement bending deformation resistance of the existing macadam base structure is poor. The geogrid-reinforced macadam base can effectively strengthen the bending resistance of the pavement, but no international consensus has been reached at present over bending failure laws of reinforced macadam base structure. Discrete element models of semi-rigid base pavement structure, macadam base pavement structure, and geogrid-reinforced macadam base pavement structure were built based on MATDEM discrete element simulation program; loading calculation of the three models was conducted by taking their centers as loading positions; and model displacement nephogram, strain nephogram, and effects of different spans on their bending deformation were analyzed to reveal bending failure laws of reinforced macadam base and improvement effect of the geogrid on the anti-bending performance of the macadam structural layer. Finally, bending deformation laws of the three pavement structures and improvement effect of geogrid reinforcement on bending properties of the macadam base structure were established. The results show that under bending deformation of semi-rigid base, the vertical strain at the contract surface between the baseplate and soil base and horizontal strain at midspan position reach the maximum, which can easily lead to fracture and shear failure, and the macadam base layer can effectively isolate the tensile strain transmitted from bottom up. Through their own deformation, grids can transform surface pressure load into frictional resistance at the geogrid/soil interface and partial kinetic energy in the system into their own elastic potential energy to reduce the kinetic energy at the subbase layer. Geogrid reinforcement can improve the nonlinearity of macadam materials, reduce the fluctuation amplitude of the strain curve and displacement curve, lengthen the service life of the macadam base pavement structure, and improve its structural soundness under bending deformation. This study can provide a theoretical reference for numerical simulation of bending failure of geogrid-reinforced macadam base.
\end{abstract}

Keywords: bending failure; discrete element method; flexible base; geogrid; graded broken stone; reinforced pavement structure

\section{INTRODUCTION}

The base is the main bearing structure in a pavement structure. A good base structure not only needs to bear traffic load but also should adapt to all kinds of external stress fields. The traditional semi-rigid base no longer conforms to the development concept of a "smart road" in China because of single structure, serious reflection track problem, and high maintenance cost. A macadam base can adapt to various external stress fields through its own aggregate rearrangement to mitigate thermal- and dryshrinkage-induced cracking of the base structure while inhibiting reflection tracks. Therefore, it will certainly become the main development direction of highway base structures in China. It is especially important to strengthen the structural performance of macadam bases, reduce their bending deformation, and promote better development of macadam bases.

Most of the existing macadam bases are non-cemented or lean-cemented, and aggregates of loose structure are tightly pressed and mutually embedded with a large displacement under load action [1]. Latticed reinforcements of geogrids can tightly lock and reinforce macadam aggregates and reduce structural displacement and strain of the macadam base under bending action. Frictional resistance at the geogrid/soil interface can effectively reduce the pressure load borne by the subbase layer, and the concrete effect is related to grid specifications [2]. Existing geogrid reinforcement technologies improve thermal- and dry-shrinkage-induced cracks on the new surface layer mostly by paving grids below the additional asphalt layer. Research on geogridreinforced macadam bases is lacking [3, 4]. Computerassisted numerical simulation has provided an efficient analytical means for research regarding macadam base and geogrid reinforcement technology with the development of computer technology, but simulation results are quite varied because complicated commercial simulation programs in the market at the present stage differ much in parameter debugging of model materials and element types, which aggravates the difficulty of theoretical research.

An integrated analysis of the existing numerical simulation research is necessary to help find numerical model methods and model parameters that are more geared to practical situations and eliminate the drawbacks of above research. Hence, discrete element simulation of bending deformation of geogrid-reinforced macadam base was proposed based on MDTDEM discrete element program, followed by a research on its bending deformation laws and geogrid reinforcement effect.

\section{STATE OF THE ART}

Research on geogrid-reinforced macadam bases as new type of reinforced macadam structure remains in the preliminary stage. Numerous international scholars have carried out much numerical simulation research on macadam base structures. Ren et al. [5] analyzed the improvement effect of the macadam base on semi-rigid subbase temperature and proposed that the macadam base could reduce or eliminate reflection cracks caused by temperature. Zhao et al. [6-8] investigated the resisting effect of the macadam stress-absorbing layer on reflection cracks under the action of external stress field via finite element 3D simulation, and their results showed that the macadam base could effectively postpone the generation of initial cracks at the semi-rigid base. Alkaissi et al. [9-11] performed a numerical simulation of macadam materials using a finite element model and pointed out that the finite element model could display the mechanical response of the flexible pavement under dynamic load and all kinds of external stress fields. Hamim et al. [12-15] studied the mechanical response model of the flexible base under various dynamic loads through a finite element 3D numerical simulation. $\mathrm{Lu}$ et al. [16] established a tirepavement coupling model by finite element method, and 
revealed the influence of tire operating conditions on pavement mechanical properties. Jiang et al. [17] constructed the graded broken stone (GBS) constitutive model and the biaxial numerical experimental method based on particle flow code. Macadam materials were regarded as finite element models in the above research, mesh generation was realized using unified element type, and discrete particles exhibited evident nonlinearity. Thus, the finite element model failed to restore the complicated mutual movement between model particles and nonlinear characteristics of materials.

Negaet al. [18] raised a new type of simplified simulation model based on shake down theory of particle layer on flexible pavement to avoid many problems of finite element method, thus simplifying the modeling and simulating the mechanical response of unconstrained particle layer to dynamic load. Cerni et al. [19] studied permanent deformation characteristics of particle materials at the pavement subbase layer through repeated triaxial loading test and finally constructed an analytical model for permanent deformation of loose particle materials based on shake down theory, which was then used to evaluate the permanent deformation performance of macadam materials. However, these models were all constructed based on shake down theory and assumed that particles had certain initial plastic deformation. Thus, they still had limitations for complicated initial particle state and relative particle movement in the macadam base.

Several scholars also conducted indoor experimental investigations on pavement performances of macadam base structures and geomaterial reinforcement technologies. Jiang et al. [20] proposed the dynamic triaxial numerical experimental method for GBS and verified its reliability by combining it with indoor dynamic triaxial loading test. Khan et al. [21] proposed that rainwater greatly influences tracks on a flexible pavement by combining pavement accelerated test results and provided the relation equation between track and passed quantity. Nagabhushana et al. [22] used the accelerated pavement test system to simulate real field load and tire pressure on the pavement, systematically studied the permanent deformation of flexible pavement based on wheel imprints on the pavement, and identified that rutting damage is more serious on flexible pavement under unidirectional load action. Kim [23] put forward constant confining pressure and variable confining pressure permanent deformation models according to the repeated load triaxial test results. Hashemolhosseini et al. [24] introduced the Barcelona basic model to explore the effect of material parameters in geocell on soil mass stability; they conducted modeling analysis via FLAC2D finite element software, and their results showed that the bending moment of geocell reinforcement is decided by the number of layers and placement depth. Most of the above research probed pavement tracks and permanent deformation performance of surface layers, but research on bending deformation performance deciding service life of pavement structure is lacking.

Given this scenario, Zhao et al. [25] simulated the loss of soil base bearing capacity under cyclic load action via a finite element model and finally determined the failure range of soil base. Combining the bending fatigue test, Saride et al. [26] proposed that a macadam-type interlayer with high interfacial shear and tensile bond performances could effectively control reflection cracks and lengthen interlayer fatigue life. Ghadimi et al. [27] used dynamic simulation to study the effect of seismic load and earth pitch interaction on flexible base. Xin et al. [28] performed static fatigue loading test of prestressed specimens and determined the amplitude coefficient during steady-state fatigue period, under severe damage, and under critical failure to predict the bending deformation laws of pavement structure under existing traffic load action. Kovrov et al. [29] constructed a rectangular cross-sectional bending moment-curvature graph of concrete bending element, verified and compared it with test data, and obtained the equations of key points, which decide crosssectional linear "bending moment-curvature" graph under different reinforcement ratios. Tomás-Espín et al. [30] compiled the design program of the optimal size of concrete section under bending stress and axial load.

These researchers focused on bending fatigue performance of a single macadam interlayer or concrete beam, but few studied bending deformation laws of geogrid-reinforced macadam bases and their bending performance.

Therefore, discrete element simulation program MATDEM was proposed in this study to numerically simulate bending load on geogrid-reinforced macadam base structure and tackle the disadvantages of existing research. Discrete element models of semi-rigid base pavement structure, macadam base pavement structure, and geogrid-reinforced macadam base pavement structure were constructed through field research data, and their centers were taken as loading positions to perform stepwise loading of the models using multiple-load steps. Based on the simulation results, displacement nephograms and strain nephograms of the models were analyzed, reasonable model spans were selected according to field research, and then effects of different spans on bending deformations of the models were analytically researched to determine bending deformation laws of the three pavement structures and the improvement effect of reinforcement on antibending performance of the macadam base structure.

The rest of this study is organized as follows: Section 3 expounds the modeling and selection of material parameters. Section 4 presents the result analysis of numerical simulation nephograms. The final section summarizes the study and draws related conclusions

\section{METHODOLOGY \\ 3.1 Software Introduction}

MATDEM used in this study is the first discrete element numerical model based on GPU matrix calculation method and 3D contact algorithm. It realizes 15,000,000 times / s 3D element movement calculation $(40,000,000$ times / $\mathrm{s}$ for 2D element movement calculation) through material self-trained command, and it can transform material macro parameters into model element parameters via macro and micro conversion formulas, and provide the final model material parameters based on multistep iteration balance inside the system to unify and standardize selection and transformation of model material parameters. The concrete conversion formulas are shown below: 


$$
E=\sigma_{z z} / \varepsilon_{z z}=\frac{6 \sqrt{2} K_{\mathrm{n}}\left(K_{\mathrm{n}}+K_{\mathrm{S}}\right)}{d\left(5 K_{\mathrm{n}}+K_{\mathrm{S}}\right)}
$$

where $E$ is the Young modulus, $\sigma_{z z}$ is the normal stress in the direction of axis $z, \varepsilon_{z z}$ is the normal strain in the direction of axis $z, K_{\mathrm{n}}$ is the normal stiffness coefficient, $K_{\mathrm{s}}$ is the tangential stiffness coefficient, and $d$ is the particle diameter.

$v=\frac{\varepsilon_{x x}}{\varepsilon_{z z}}=\frac{K_{\mathrm{n}}-K_{\mathrm{S}}}{5 K_{\mathrm{n}}+K_{\mathrm{S}}}$

where $v$ is Poisson's coefficient, and $\varepsilon_{x x}$ is the forward strain in the direction of axis $x$.

$T_{\mathrm{u}}=\frac{6 \sqrt{2} K_{\mathrm{n}}\left(K_{\mathrm{n}}+K_{\mathrm{S}}\right)}{3 K_{\mathrm{n}}+K_{\mathrm{S}}} \cdot \frac{X_{\mathrm{b}}}{d^{2}}$

where $T_{\mathrm{u}}$ is the material tensile strength.

$C_{\mathrm{u}}=\frac{6}{1-\sqrt{2} \mu_{\mathrm{p}}} \cdot \frac{F s_{0}}{d^{2}}$

where $C_{\mathrm{u}}$ is the material compressive strength.

$$
\left\{\begin{array}{l}
\mu_{i}=\frac{P-1}{2 \sqrt{P}} \\
P=\frac{2+\sqrt{2} \mu_{\mathrm{p}}}{1-\sqrt{2} \mu_{\mathrm{p}}}
\end{array}\right.
$$

where $\mu_{i}$ is the angle of internal frictional of material, and $\mu_{\mathrm{p}}$ is the element friction coefficient.

$K_{\mathrm{n}}=\frac{\sqrt{2} E d}{4(1-2 v)}$

$K_{\mathrm{S}}=\frac{\sqrt{2}(1-5 v) E d}{4(1+v)(1-2 v)}$

$X_{\mathrm{b}}=\frac{3 K_{\mathrm{n}}+K_{\mathrm{S}}}{6 \sqrt{2} K_{\mathrm{n}}\left(K_{\mathrm{n}}+K_{\mathrm{S}}\right)} \cdot T_{\mathrm{u}} \cdot d^{2}$

where $X_{\mathrm{b}}$ is the fracture displacement.

$F s_{0}=\frac{1-\sqrt{2} \mu_{\mathrm{p}}}{6} \cdot C_{\mathrm{u}} \cdot d^{2}$

where $F_{S_{0}}$ is the element shear resistance.

$$
\left\{\begin{array}{l}
\mu_{\mathrm{p}}=\frac{-2 \sqrt{2}+\sqrt{2} I}{2+2 I} \\
I=\left[\left(1+\mu_{i}^{2}\right)^{1 / 2}+\mu_{i}\right]^{2}
\end{array}\right.
$$

\subsection{Discrete Element Modeling}

Three discrete element models were used for a comparative analysis. The following hypotheses were made to restore the geogrid/soil interaction better:

(1) The geogrid can only bear tensile load but not compressive load.

(2) The model reaches theoretical maximum compactness through gravitational stacking, extrusion, and compaction in the initial phase, which satisfies the requirements of engineering practice.

(3) The unified shape and dimension of particle elements are used in all models.

\subsubsection{Model Layering and Dimensions}

(1) Structural Model of Semi-rigid Base Pavement

The overall pavement structure was $30 \mathrm{~cm}$ in thickness, and the thickness values of the cement-stabilized macadam base and asphalt concrete pavement were 24 and $5 \mathrm{~cm}$, respectively (Fig. 1).

(2) Structural Model of Macadam Base Pavement

The overall thickness of the pavement, cementstabilized macadam base, graded macadam base, and asphalt pavement were 30, 15, 9 and $6 \mathrm{~cm}$, respectively. The concrete model is shown in Fig. 2.

(3) Structural Model of Geogrid-reinforced Macadam Base Pavement

Geogrids were added on the macadam base pavement structure. Biaxial tensile fiberglass geogrids were used in this study, the grids were set into clump elements to prevent their failure during loading, and grid elements were connected to cement-stabilized macadam layer and macadam layer to simulate occlusal contact between geogrids and aggregates, as shown in Fig. 3.

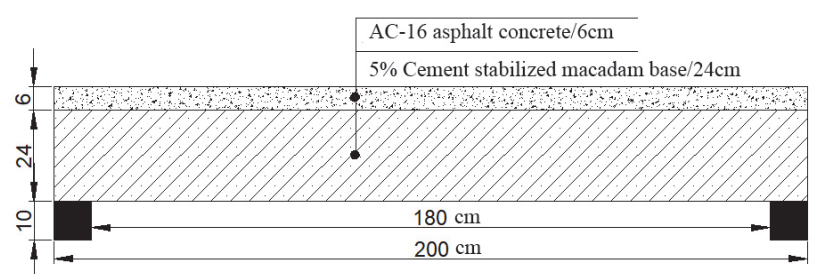

Figure 1 Semi-rigid base pavement structure/cm

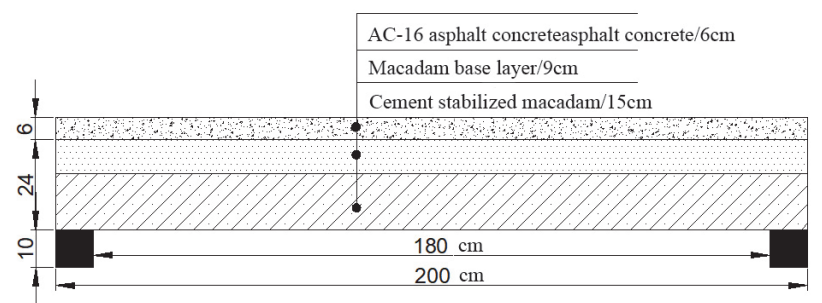

Figure 2 Macadam base pavement structure/cm

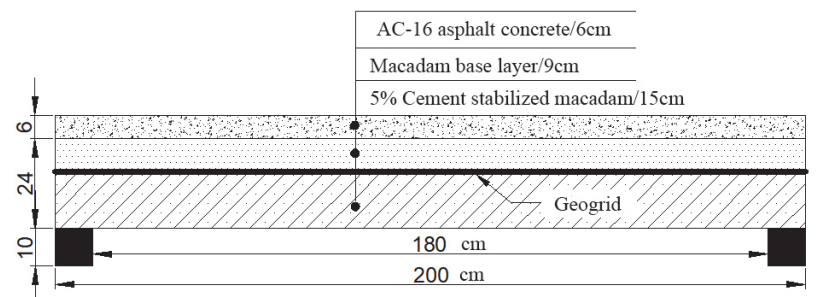

Figure 3 Reinforced macadam base pavement structure/cm 


\subsubsection{Determination of Model Boundary Conditions}

The degree of freedom of grid elements in the horizontal direction was restricted to simulate the action of lateral geogrid reinforcement, and a model casing was set as model boundary and connected to model boundary elements by default to simulate boundary constraint borne by the pavement in a practical situation. Cement-stabilized macadam materials and asphalt materials were cemented, and cementing strength was the default strength parameter of the system. Grid elements were connected to cementstabilized macadam layer and macadam layer to simulate the occlusal contact between grids and aggregates.

\subsubsection{Model Calculation Parameters}

Macro material parameters of the models are shown in Tab. 1.

Table 1 Material macro parameters

\begin{tabular}{|c|c|c|c|c|}
\hline Material name & $\begin{array}{c}\text { Young } \\
\text { modulus } E / \\
\mathrm{GPa}\end{array}$ & $\begin{array}{c}\text { Poisson's } \\
\text { coefficient } \\
v\end{array}$ & $\begin{array}{c}\text { Material } \\
\text { compressive } \\
\text { strength } \\
C_{\mathrm{u}} / \mathrm{MPa}\end{array}$ & $\begin{array}{c}\text { Density } \\
\mathrm{g} / \mathrm{cm}^{3}\end{array}$ \\
\hline $\begin{array}{c}\text { Graded broken } \\
\text { stone }\end{array}$ & 0.55 & 0.25 & 1.43 & 2.10 \\
\hline $\begin{array}{c}5 \% \text { Cement } \\
\text { Stabilized } \\
\text { Macadam }\end{array}$ & 1.4 & 0.25 & 5.30 & 2.20 \\
\hline $\begin{array}{c}\text { Asphalt } \\
\text { Concrete }\end{array}$ & 1.2 & 0.45 & 0.80 & 2.00 \\
\hline Geogrid & 0.468 & 0.25 & - & - \\
\hline
\end{tabular}

\subsection{Numerical Simulation Analysis of Structural Bending Deformation}

The subbase layer will gradually separate from the soil base, and a structural model similar to simply supported beam will finally form with the continuous subsidence of the soil base. Mass bending deformation occurs to the pavement structure under the action of traffic loads, and minor bending deformation will rebound after unloading. A certain soil base subsidence was assumed in this study to restore the bending deformation of subgrade structure. Thus, the subbase layer was separated from the soil base, and a mechanical model of simply supported beam was formed. Before numerical calculation, each model was made to reach initial balance under the effect of gravity, and then the model center was taken as loading position to perform stepwise loading calculation of the three pavement structures. Following loading, strain and displacement nephograms in various directions were output to analyze their bending deformations.

\subsection{Effect of Different Spans on Bending Deformations of the Three Pavement Structures}

Field investigation showed that the baseplate gapped span would generally not exceed the length of an oversized vehicle. The span was elevated from $2 \mathrm{~m}$ (length of small vehicle) to $5 \mathrm{~m}$ (length of oversized vehicle) to investigate the effect of baseplate gapped span on the strain and displacement of the three pavement structures and simulate the effect of span on the structural deformation by applying the same central load.

\section{RESULT ANALYSIS AND DISCUSSION}

\subsection{Simulation Analysis of Bending Deformation of the Semi-rigid Base Pavement Structures}

Strain nephogram and displacement nephogram obtained through simulation are shown in Figs. 4, 5, 6 and 7.

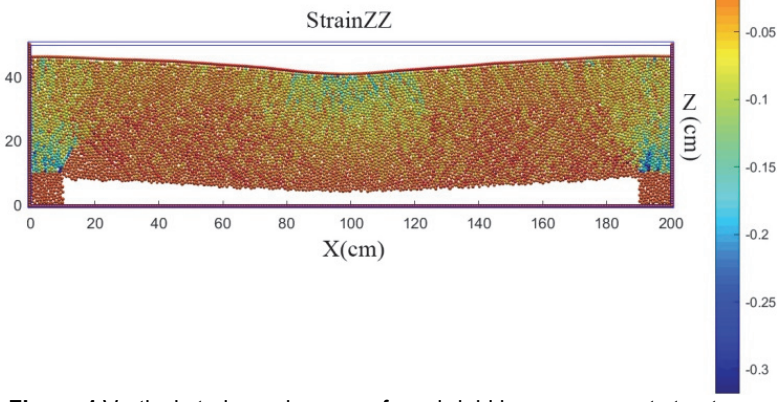

Figure 4 Vertical strain nephogram of semi-rigid base pavement structure

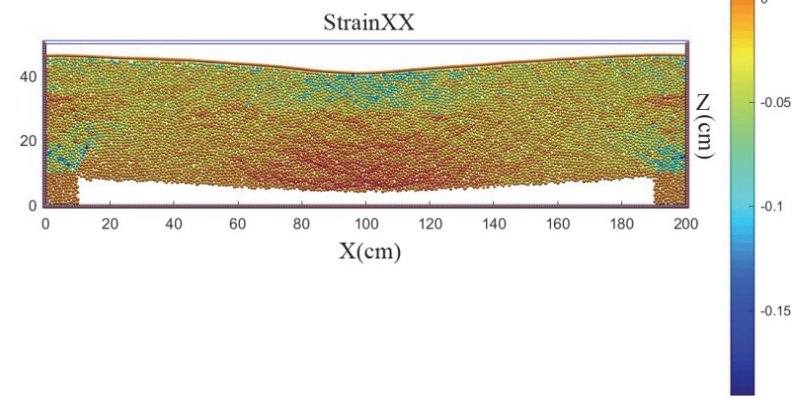

Figure 5 Horizontal strain nephogram of semi-rigid base pavement structure

Figs. 4 and 5 show that when the semi-rigid base pavement bore vertical compressive stress at midspan position, the strain nephogram distribution of aggregate particles followed the extending direction of particle force chain, and a large vertical strain was generated in the local load-bearing region of the surface layer. The diffusion of vertical compressive strain along the depth direction was small owing to the influence of material stiffness and lateral boundary constraint. The compressive strains at the two-sided boundary of the model and nearby base abutment reached the maximum values, and so did the horizontal stress and strain at the midspan position of the base structure. Under long-term cyclic load action, bending cracks would be generated first at these positions with large strains.

Figs. 6 and 7 show that the vertical displacement of the semi-rigid base pavement structure presented stripped progressive decreasing trend along the midspan toward the two-sided boundary, and an evident boundary zone formed near the support. The horizontal displacement nephogram was divided into four triangular Regions I-IV from left to right, three regional boundaries all started from the loadbearing point and pointed to the midspan position on the undersurface and two-sided supports, and the displacement 
directions of adjacent regions were the opposite. The displacements in Regions I and IV progressively decreased along the depth direction, while those in Regions II and III progressively increased along the depth direction. From the displacement distribution, three major cracks could be easily generated under long-term bending deformation of the semi-rigid base pavement structure, that is, three boundaries of horizontal displacement regions. The strain distribution positions show that initial cracks at the midspan were generated on the base layer and then continuously transferred to the surface layer. Finally, a through failure plane was formed, where two-sided cracks were generated on the upper and lower surfaces and gradually extended inside the structural layer until becoming through cracks.

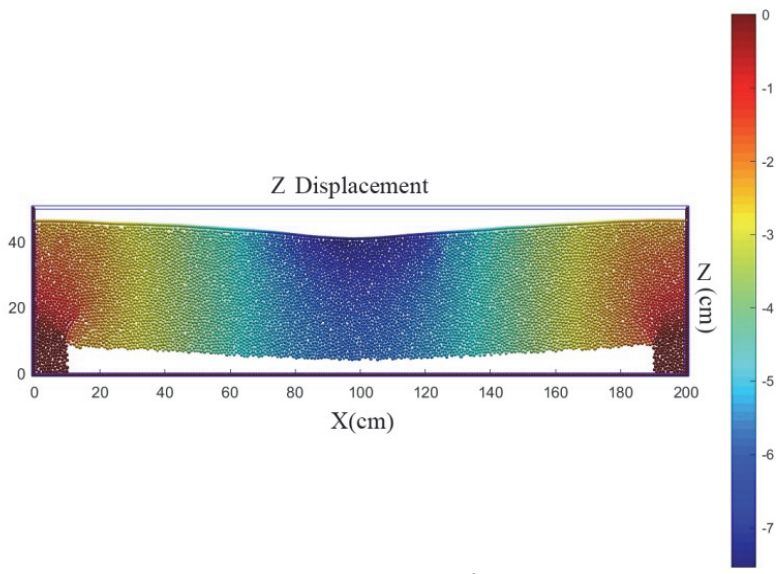

Figure 6 Vertical displacement nephogram of semi-rigid base pavement structure

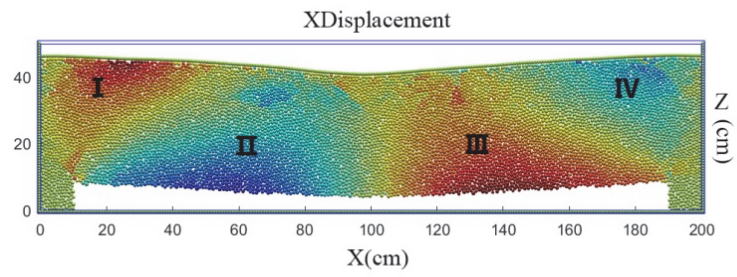

Figure 7 Horizontal displacement nephogram of semi-rigid base pavement structure

\subsection{Simulation Analysis of Bending Deformation of the Macadam Base Structure}

Strain nephogram and displacement nephogram obtained through simulation are shown in Figs. 8, 9, 10 and 11.

Figs. 8 and 9 show that after the macadam base was added, the vertical strain of the pavement was enlarged, while its structural stiffness and mean rebound modulus were reduced. The vertical strains at midspan of the macadam base and nearby two-sided boundary were the maximum. Compared with the semi-rigid base pavement, the horizontal strain distribution was uniform on the macadam base, which could effectively isolate the tensile strain extended from bottom up.

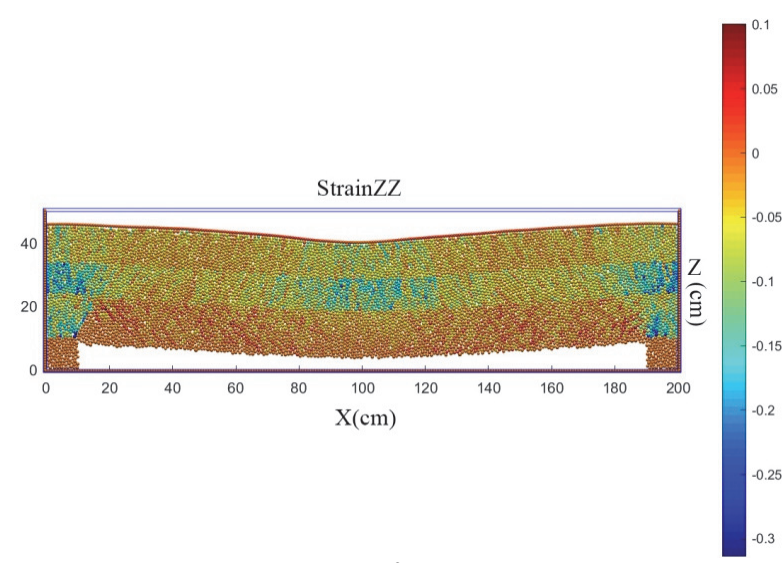

Figure 8 Vertical strain nephogram of macadam base pavement structure

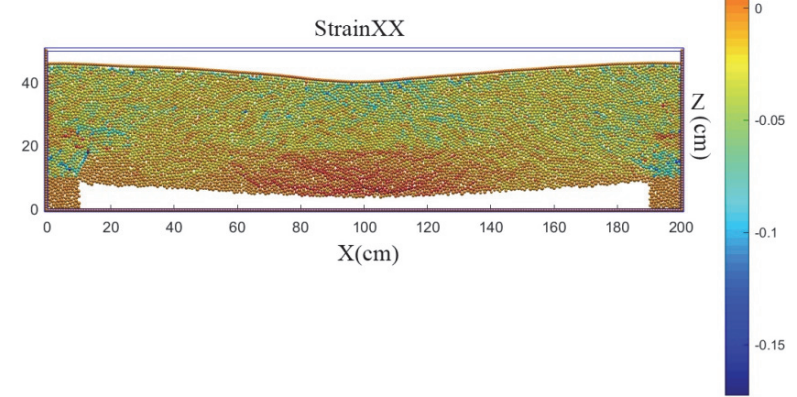

Figure 9 Horizontal strain nephogram of macadam base pavement structure

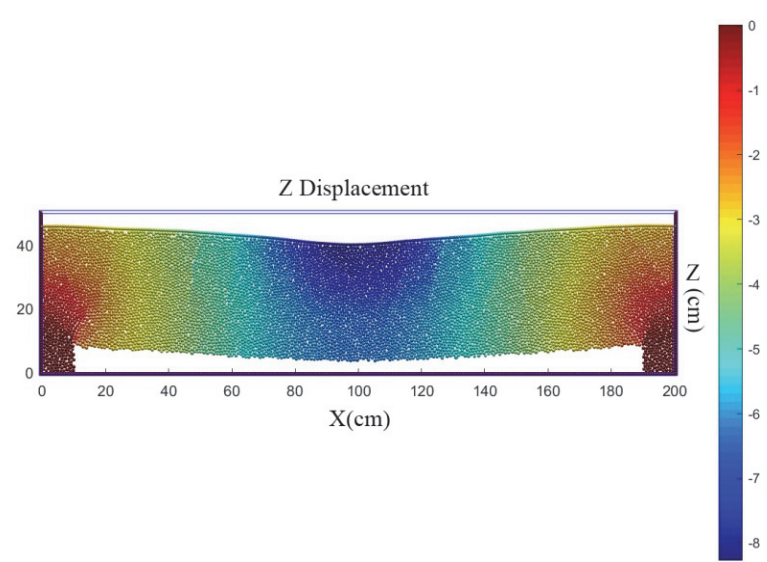

Figure 10 Vertical displacement nephogram of macadam base pavement structure

Figs. 10 and 11 show that after the macadam base was added, the macadam particles were rearranged after being compressed, the horizontal displacement of the pavement structure was evidently enlarged, and the ranges of displacement distribution in Regions I and IV were expanded. Fig. 11 shows that the horizontal displacement at the macadam base and subbase contact plane were small, and a clear interlayer horizontal displacement zone was formed.

In summary, compared with the semi-rigid base pavement, the horizontal strain of the macadam base became uniform, which could effectively isolate the horizontal tensile strain generated at the cement-stabilized 
macadam layer, but the overall bearing capacity of the pavement was poor, the vertical strain and horizontal displacement in the macadam base were enlarged to a great extent, and the bending deformation of the pavement structure was serious.

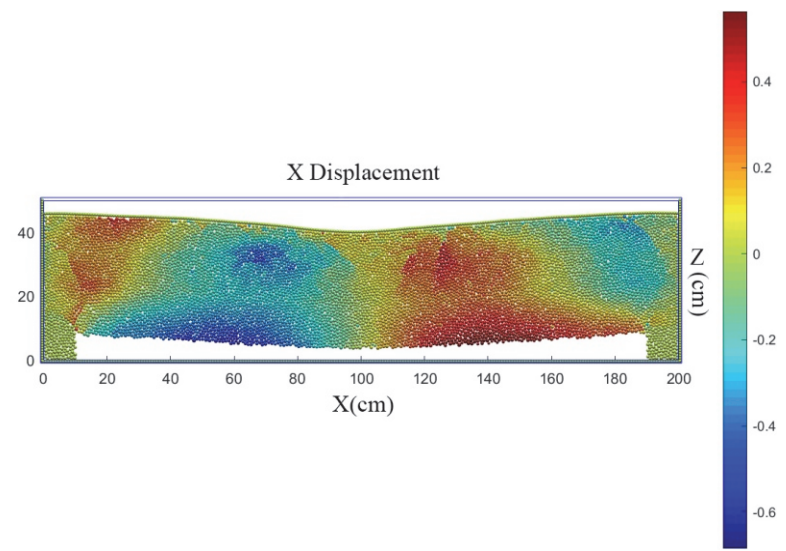

Figure 11 Horizontal displacement nephogram of macadam base pavement structure

\subsection{Bending Simulation Analysis of Geogrid-reinforced Macadam Asphalt Pavement}

Nephograms obtained through simulation are shown in Figs. 12 and 13.

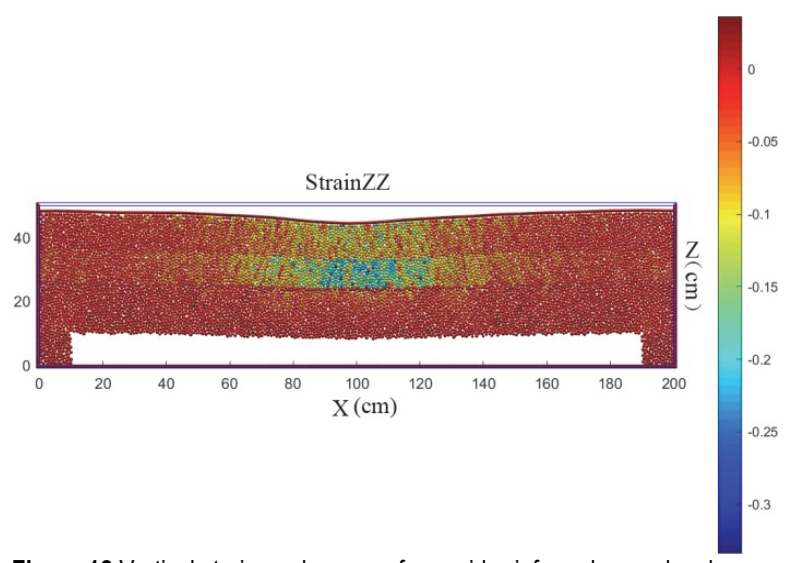

Figure 12 Vertical strain nephogram of geogrid-reinforced macadam base structure

Figs. 12 and 13 show that the macadam base and asphalt concrete pavement would be further compacted when bearing load, and local vertical compressive strain at the load-bearing point was increased due to the interlocking effect of grids. The geogrids transformed the pressure load into frictional resistance at the geogrid/soil interface through their own tensile deformation. Thus, the overall bending strain of the pavement structure was improved greatly. Comparing Figs. 8 and 12 shows that the vertical compressive strain of single macadam base was averagely stabilized within the interval of $0.05-0.1$, that in the geogrid-reinforced macadam base within the interval of 0-0.5 decreased by $50 \%$, and no evident vertical strain was observed beyond the $60 \mathrm{~cm}$ distance range from the midspan.

Displacement nephograms obtained through simulation are shown in Fig. 14 and 15.

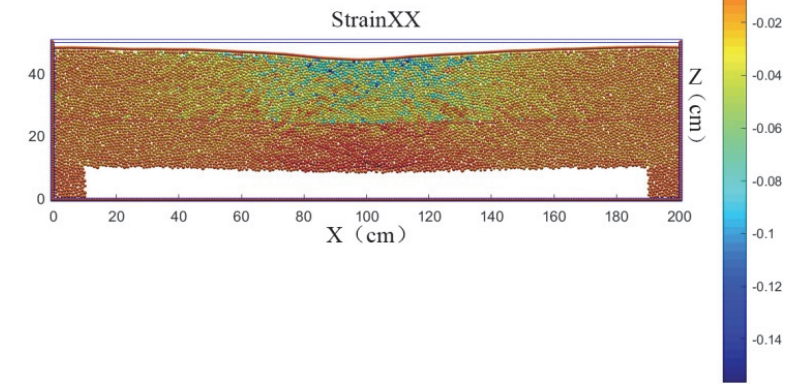

Figure 13 Horizontal strain nephogram of geogrid-reinforced macadam base structure

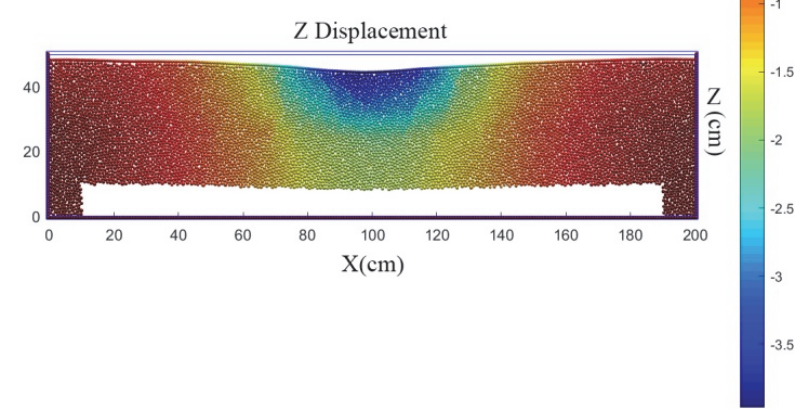

Figure 14 Vertical displacement nephogram of geogrid-reinforced macadam base structure

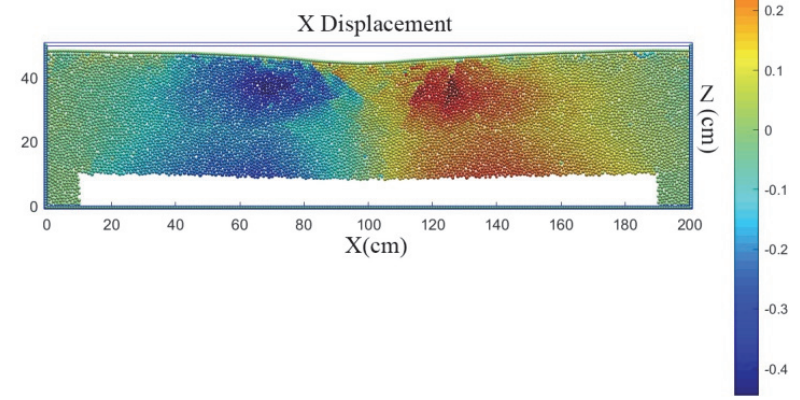

Figure 15 Horizontal displacement nephogram of geogrid-reinforced macadam base structure

Figs. 14 and 15 show that the vertical displacement of the geogrid-reinforced macadam base structure was concentrated at the asphalt surface while the displacement on the subbase layer was small, the displacement bands were clearly distributed in the region near the midspan, and no evident vertical displacement distribution was observed at the two-sided boundary. Comparing Figs. 11 and 15 shows that after geogrids were added, the overall lateral displacements on the macadam base and asphalt surface were enlarged, but the lateral displacement near the boundary was reduced by a large margin. Relative to Fig. 7, the lateral displacement distribution in the geogridreinforced macadam base structure was more uniform, the lateral displacement on the subbase layer was reduced 
somehow, and no evident regional demarcation was observed near the two-sided boundary.

In conclusion, geogrids can transform traffic loads at the surface layer of the pavement structure into frictional resistance at the geogrid/soil interface, which points to the two-sided boundary along the grid surface through their own deformations to reduce the vertical load borne by the subbase layer. Moreover, the action of the geogrid reinforcement can effectively mitigate the vertical strain of the macadam base, facilitate the uniform lateral displacement distribution at the boundary of the base structure, eliminate the interface of lateral displacements of the macadam base, and postpone the generation of bending cracks at this position. The latticed structure of the geogrids can restrict the lateral movement of aggregates in the macadam base and reduce the interlayer translation between the macadam base and subbase layer.

\subsection{Simulation Analysis of Effect of Different Spans on Bending Deformations of the Three Pavement Structures}

\subsubsection{Effect of Span on Vertical Normal Strain}

The simulation results were drawn into point-line graphs as shown in Figs. 16 and 17.

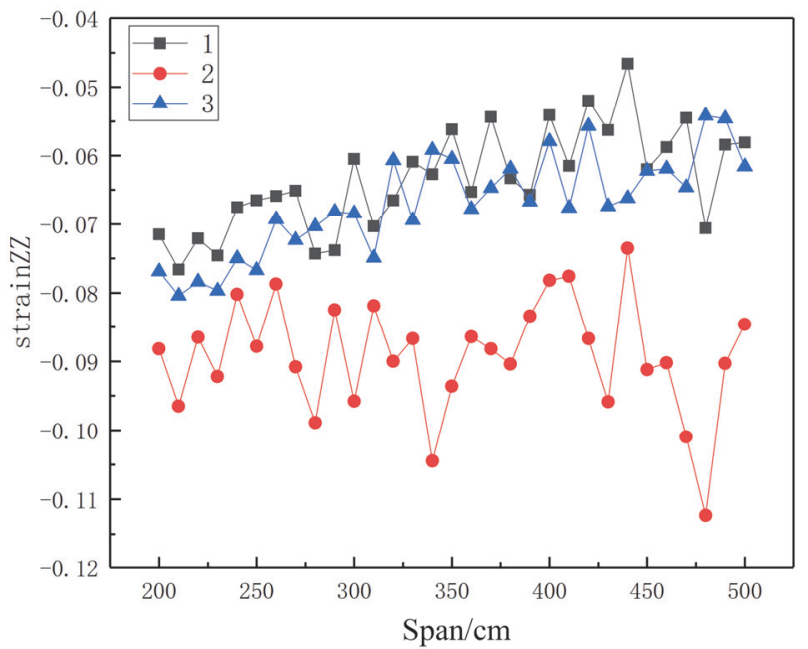

Figure 16 Relationship curve between vertical compressive strain and span (1) Semi-rigid base asphalt pavement structure; (2) Macadam base asphalt pavement structure; (3) Geogrid-reinforced base asphalt pavement structure

The simulation results in Fig. 16 reflect the nonlinear characteristics of macadam materials. The vertical tensile strains of the three pavement structures irregularly fluctuated with the span change, the vertical compressive strain of the macadam base pavement structure was the maximum and was higher than that of the semi-rigid base pavement structure by $50 \%$, and the curve displayed evident nonlinearity with the maximum fluctuation amplitude. The vertical compressive strain curves of the reinforced macadam base structure and semi-rigid base pavement presented a rising tendency with approximate fluctuation amplitudes.

Fig. 17 shows that the vertical tensile strain of the semi-rigid base pavement was the maximum with the most apparent curve fluctuation amplitude. The vertical tensile strain of the macadam base structure was high within a small span range, rapidly dropped as the span increased from $200 \mathrm{~cm}$ to $300 \mathrm{~cm}$, and then gradually stabilized without evident change after the span reached $300 \mathrm{~cm}$. Under a small span, a large extrusion force was generated between GBS aggregates due to load action; the aggregate particles, which were tightly occlusive at the beginning, underwent shear dilation phenomenon under extrusion force; and the vertical tensile strain was large. As the span increased, the extrusion force between aggregates was transmitted along the span length direction through the occlusal contact between particles, the originally loose particles were further compacted, the aggregate particles were rearranged, the extrusion force was effectively buffered, and the shear dilation phenomenon was relieved; thus, the vertical tensile strain in the structure was rapidly reduced. After geogrids were added, transverse and longitudinal fibers in the geogrids would restrict aggregate displacement in the macadam base, effectively mitigate the shear dilation phenomenon of the macadam base pavement structure after load bearing, improve the nonlinearity of vertical tensile strain curve, and reduce the fluctuation amplitude of the curve.

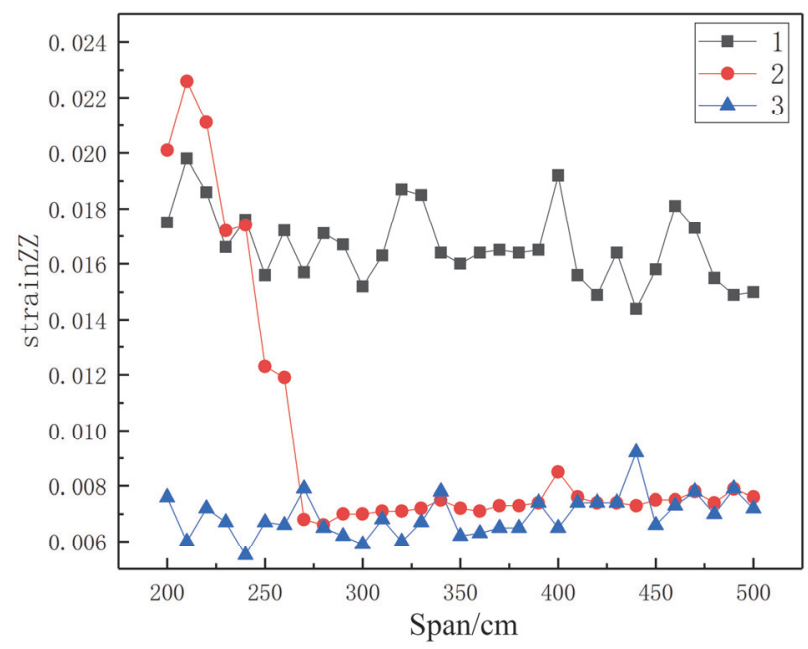

Figure 17 Relationship curve between vertical tensile strain and span

\subsubsection{Effect of Span on Horizontal Normal Strain}

The simulation results were drawn into point-line graphs as shown in Figs. 18 and 19.

Fig. 18 shows that the horizontal compressive strains of the three pavement structures all presented a nonlinear irregular fluctuation. The horizontal compressive strain of the semi-rigid base pavement was evidently lower than those of the other two, and the fluctuation amplitudes of horizontal compressive strain curves of the macadam base structure and geogrid-reinforced macadam base structure were gradually reduced with the increase of span, indicating that the nonlinearity of horizontal compressive strain curves of the two pavement structures was negatively correlated with the span, and their curvilinear trends were approximate without apparent difference.

Fig. 19 shows that the span-dependent change trend of horizontal tensile strain of the macadam base structure was similar to that of its vertical tensile strain for the reason same as above. The horizontal tensile strain curve of the reinforced macadam base structure was located between those of the semi-rigid base pavement and macadam base structure because geogrids would experience a large 
deformation, the grids would rapidly be tensioned and shrunk, and the frictional resistance at the geogrid/soil interface and occlusal force would force the aggregate displacement at the flexible layer under bending deformation of pavement structure. Therefore, the horizonal tensile strain of the reinforced macadam base structure was increased, but the strain curve fluctuation was the most stable under the action of geogrid reinforcement.

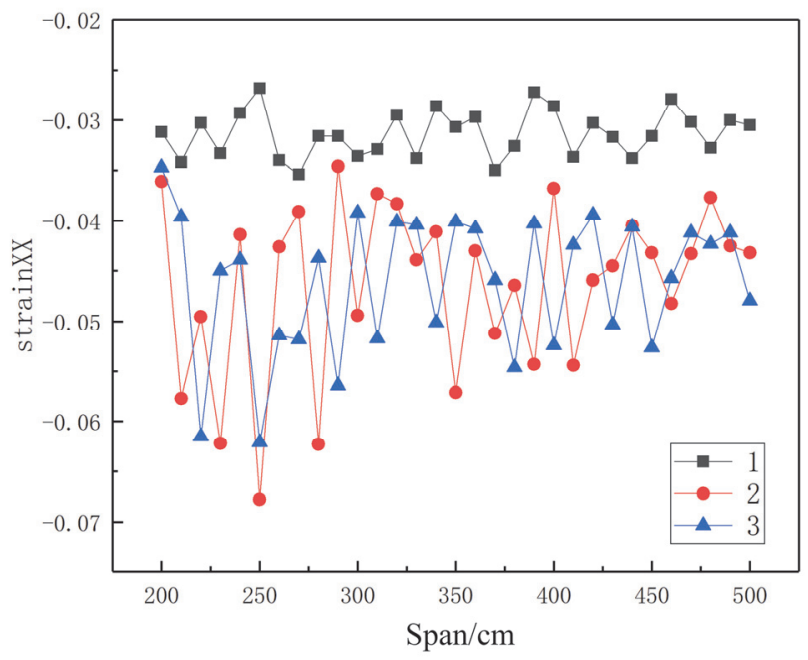

Figure 18 Relationship curve between horizontal compressive strain and span

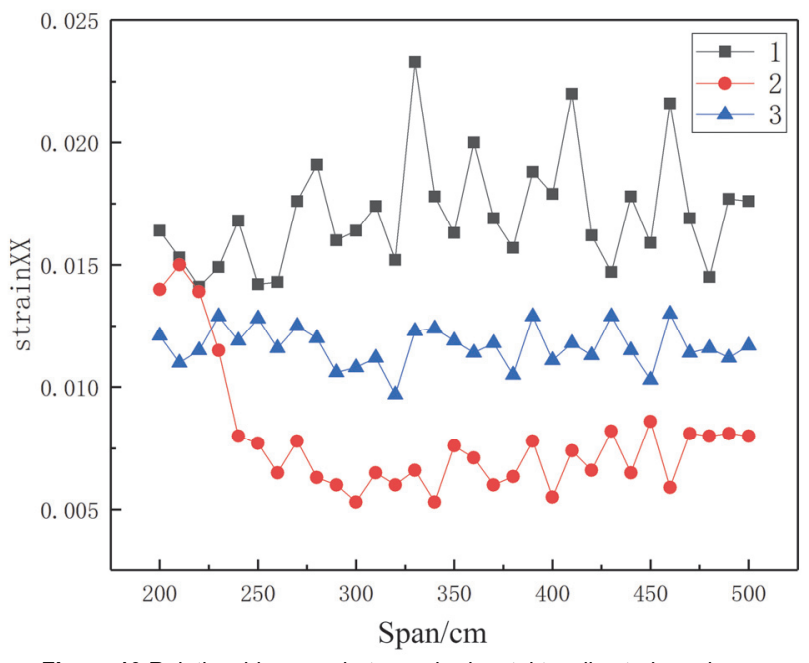

Figure 19 Relationship curve between horizontal tensile strain and span

\subsubsection{Effect of Span on Displacement}

The point-line graph of vertical displacement is shown in Fig. 20.

The results showed that the absolute vertical displacements of the pavement structures presented a linear progressive growth with the increase of span, where the vertical displacement of the macadam base pavement structure was the maximum, that of the semi-rigid base pavement structure was approximate, and their slopes were both -0.008 , manifesting that only adding macadam base did not exert any evident improvement effect on the vertical displacement at the surface layer of the pavement structure. After geogrids were added, the slope of vertical displacement curve of the macadam base pavement structure was clearly reduced due to the action of geogrid reinforcement, and the slope of the displacement curve was lowered to -0.003 . This finding meant that the geogrid reinforcement could effectively reduce the vertical displacement of the macadam base pavement structure, relieve the span-dependent growth rate of its vertical displacement, and reduce its bending deformation.

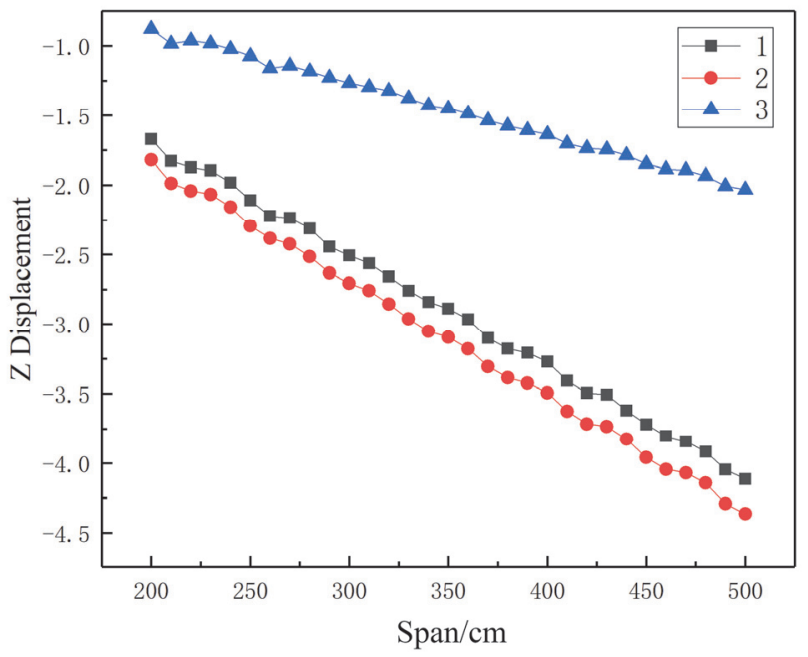

Figure 20 Relationship curve between vertical displacement and span

The point-line graph of horizontal displacement is shown in Fig. 21.

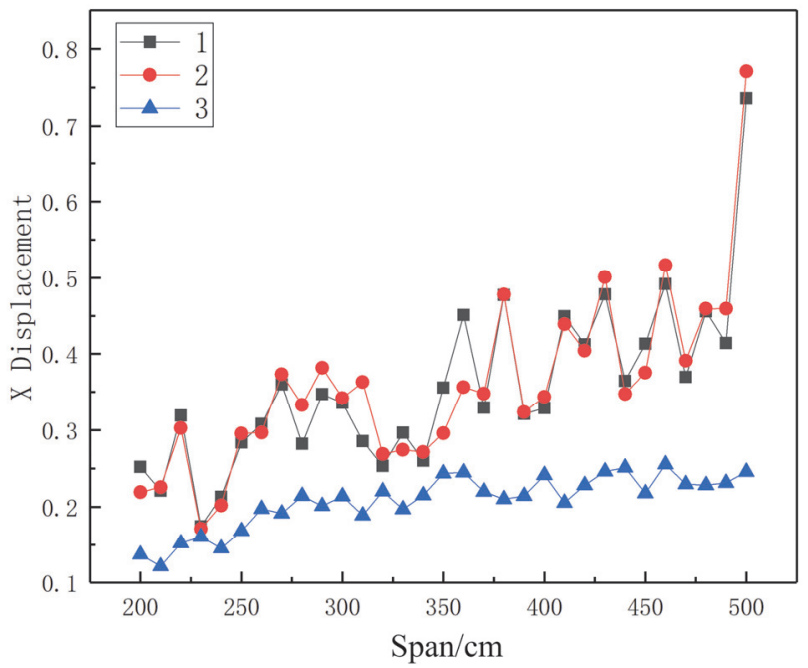

Figure 21 Relationship curve between horizontal displacement and span

Fig. 21 shows that the horizontal displacement curves of the three pavement structures all presented a nonlinear fluctuation with the increase of span. The horizontal displacement of the semi-rigid base pavement structure approximated that of the macadam base pavement structure, that is, both presented a span-dependent rising trend with a large fluctuation range and an evident curve nonlinearity. After geogrids were added, the curve steadily fluctuated with the increase of the span, the horizontal displacement of the pavement structure was reduced greatly, and the curve nonlinearity was clearly improved. These results indicated that geogrids could effectively reduce the horizontal bending deformation of the pavement structure, improve the nonlinearity of its horizontal displacement curve, and strengthen the structural stability under bending deformation. 


\section{CONCLUSIONS}

This study aimed to explore bending failure laws of the geogrid-reinforced macadam base structure and reinforcing effect of geogrids on the macadam base. MATDEM discrete element simulation software was used to perform stacking modeling and stress loading calculation of the semi-rigid base pavement structure, macadam base pavement structure, and geogrid-reinforced macadam base pavement structure. Effects of different spans on bending deformations of the three pavement structures were analyzed, and the following research conclusions were mainly drawn:

(1) The vertical strains near the abutment of the semirigid base pavement and horizontal strain at the midspan position were the maximum, where fracture and shear failure could easily occur. Initial bending cracks could be easily generated at the boundary of the base and central region on the undersurface, and three major cracks would be finally formed.

(2) The macadam base had poor bearing capacity, strong resistance to tension, and uniform horizontal tensile strain, which could isolate tensile strain at the cementstabilized macadam layer. The stability of compressive strains in all directions under different spans was poor. The stability of the horizontal compressive strain was improved with the increase span and then stabilized.

(3) Geogrids reduced the bending deformation at the base layer, restricted the lateral displacement of aggregates, reduced the horizontal displacement near the structural boundary, and postponed the generation of initial bending cracks near the two-sided boundary by transforming the load into interfacial frictional resistance.

(4) The semi-rigid base had a strong bearing capacity and a poor resistance to tension. The stability of compressive strains in various directions under different spans was relatively satisfactory, whereas that of tensile strains was poor. The geogrid-reinforced macadam base possessed favorable bearing capacity and tensile strength, the tensile strains in all directions had superior stability to those of the semi-rigid base under different spans, and the tensile strain presented no apparent change trend with the increase of span.

(5) As the span increased, the vertical displacements of the three structures presented a linear progressive increase, while their horizontal displacements presented a nonlinear progressive increase. The horizontal displacements of the semi-rigid base and macadam base structures had poor stability under different spans with high growth rate. The horizontal displacement of the geogrid-reinforced macadam base structure showed good stability under different spans and grew slowly.

The discrete element simulation analysis method adopted in this study effectively reproduced the relative movement of aggregate particles and material nonlinearity in the macadam base, clearly reflected bending deformation laws of the three pavement structures under compression state, and laid a foundation for further analyzing the anti-bending fatigue performance of the macadam base. The simulation results showed that grid reinforcement could effectively reduce the vertical displacement of the macadam base structure and slow down the growth of its vertical displacement with the increase of span. The geogrid reinforcement could relieve the fluctuation of displacement and strain curves of the macadam base structure, reduce the curve fluctuation amplitudes, and strengthen the structural stability when bending deformation was generated under different spans. Only initial bending failure laws of the three pavement structures and the influence trend of span on their displacement strain curves could be obtained in this study due to restrictions of particle shape and loading mode of the models. Effects of different loading modes and forms on the bending fatigue life of pavement structures will be included in an in-depth analysis in future research, thus contributing more to research on the bending fatigue performance of the reinforced macadam bases.

\section{REFERENCES}

[1] Yi, X. Y. (2013). Application of Graded Gravel in the Flexible Road Base. Highway Engineering, 38(4), 13-16.

[2] Wang, J. Q., Bai, L., Tang, Y., \& Zhang, L. L. (2020). Numerical Analysis of Bearing Characteristic of Geogrid Reinforced Foundation. Science Technology and Engineering, 20(13), 5269-5275.

[3] Zhang, H. W., Hao, P. W., Tang, C., \& Pang, Y. (2017). Adherence of Geotextile Interlayer in Asphalt Overlay. Journal of building materials, 20(5), 765-751. https://doi.org/10.3969/j.issn.1007-9629.2017.05.015

[4] Ye, H. Y., Wang, X. C., Fang, N. R., Su, Z. Y., \& Sun, X. W. (2020). Study on grading and treatment of asphalt pavement of the airport in a hot and humid area. Engineering Journal of Wuhan University, 53(2), 123-131. https://doi.org/10.14188/j.1671-8844.2020-02-005

[5] Ren, R. B., Zhong, D. H., Li, H. Z., An, Z. Y., \& Wang, Z. R. (2004). Theoretical analysis of improved semi-rigid bottom base temperature by flexible base in asphalt pavement. Journal of Harbin Institute of Technology, 36(9), 1280-1281. https://doi.org/10.3321/j.issn:0367-6234.2004.09.036

[6] Zhao, Y. T. (2014). Theoretical analysis and experimental study of stress absorbing layer to pavement reflection crack in half rigid pavement. Master's Thesis of Hebi University of Technology, 10-30. https://doi.org/10.7666/d.D681033

[7] Wang, S. Q., Huang, X. M., Ma, T., Zhu, T. Y., Tang, T., \& Liu, W. C. (2015). Numerical analysis of reflective cracking and fatigue lives of semi-rigid pavement structures using ABAQUS and FE-SAFE. Journal of Southeast University (English Edition), 31(4), 541-546. https://doi.org/10.3969/j.issn.1003-7985.2015.04.019

[8] Lv, L. X., (2018). Analysis on the Numerical Simulation of Reflection Crack Control of Rigid-flexible Joint Asphalt Concrete Pavement. Subgrade Engineering, (2), 57-60. https://doi.org/10.13379/j.issn.1003-8825.2018.02.13

[9] Alkaissi, Z. A. (2020). Effect of high temperature and traffic loading on rutting performance of flexible pavement. Journal of King Saud University-Engineering Sciences, 32(1), 1-4. https://doi.org/10.13379/j.issn.1003-8825.2018.02.13

[10] Judycki, J. (2010). Determination of equivalent axle load factors on the basis of fatigue criteria for flexible and semirigid pavements. Road Materials and Pavement Design, $11(1), 187-202$. https://doi.org/10.1080/14680629.2010.9690266

[11] Kostyuk, A., Kovtunenko, D., \& Kovtunenko, A. (2019). The stress-strain state of horizontal joints of wall panels. Technical Gazzete, 13(1), 7-11. https://doi.org/10.31803/tg-20180514083545

[12] Hamim, A., Yusoff, N. I. M., Ceylan, H., Rosyidi, S. A. P., \& El-Shafie, A. (2018). Comparative study on using static and dynamic finite element models to develop FWD measurement on flexible pavement structures. Construction and Building Materials, (176), 583-592. 
https://doi.org/10.1016/j.conbuildmat.2018.05.082

[13] Casey, D. B., Collop, A. C., Airey, G. D., \& Grenfell, J. R. (2012, June). The effects non-uniform contact pressure distribution has on surface distress of flexible pavements using a finite element method. Proceeding of $7^{\text {th }}$ RILEM International Conference on Cracking in Pavements, 347357. https://doi.org/10.1007/978-94-007-4566-7_34

[14] Ozer, H., Al-Qadi, I. L., \& Duarte, C. A. (2011). A threedimensional generalised finite element analysis for the nearsurface cracking problem in flexible pavements. International Journal of Pavement Engineering, 12(4), 407419. https://doi.org/10.1080/10298436.2011.575139

[15] Kim, M., Tutumluer, E., \& Kwon, J. (2009). Nonlinear pavement foundation modeling for three-dimensional finiteelement analysis of flexible pavements. International Journal of Geomechanics, 9(5), 195-208. https://doi.org/10.1061/(ASCE)1532-3641(2009)9:5(195)

[16] Lu, Y. J., Wang, L. J., Yang, Q., \& Ren, J. Y. (2018). Analysis of asphalt pavement mechanical behaviour by using a tire-pavement coupling model. International Journal of Simulation Modelling, 17(7), 245-256. https://doi.org/10.2507/IJSIMM17(2)423

[17] Jiang, Y. J., Li, S. W., Chen, Z. J., \& Fang, J. (2015). Biaxial Numberical Simulation on Graded Broken Stone and Its Influence Factors. Journal of Tongji University(Natural Science), 43(7), 1045-1050. https://doi.org/10.11908/j.issn.0253-374x.2015.07.013

[18] Nega, A., Nikraz, H., \& Al-Qadi, I. L. (2015). Simulation of shakedown behavior for flexible pavement's unbound granular layer. Airfield and Highway Pavements, 801-812. https://doi.org/10.1061/9780784479216.071

[19] Cerni, G., Cardone, F., Virgili, A., \& Camilli, S. (2012). Characterisation of permanent deformation behaviour of unbound granular materials under repeated triaxial loading. Construction and Building Materials, 28(1), 79-87. https://doi.org/10.1016/j.conbuildmat.2011.07.066

[20] Jiang, Y. J., Chen, Z. J., Li, S. W., \& Cao, F. (2015).Plastic Deforation Characteristics and Numerical Simulation of Shakedown Behavior of Graded Broken Stone. Journal of Tongji University (Natural Science), 43(6), 872-876. https://doi.org/10.11908/j.issn.0253-374x.2015.06.010

[21] Khan, S., Nagabhushana, M. N., Tiwari, D., \& Jain, P. K. (2016). Comparison of Uni and Bi-directional Load Induced Rutting in Flexible Pavement with Accelerated Pavement Testing Facility (APTF). Transportation Research Procedia, 17, 521-528. https://doi.org/10.1016/j.trpro.2016.11.106

[22] Nagabhushana, M. N., Tiwari, D., \& Jain, P. K. (2013). Rutting in flexible pavement: an approach of evaluation with accelerated pavement testing facility. Procedia Social and Behavioral Sciences, 104, 149-157. https://doi.org/10.1016/j.sbspro.2013.11.107

[23] Kim, I. T. (2005). Permanent deformation behavior of airport flexible pavement base and subbase courses. University of Illinois at Urbana-Champaign, 44-117.

[24] Hashemolhosseini, H. \& Mirmohamadsadeghi, M. (2020). Investigating the Effect of Geocell Changes on Slope Stability in Unsaturated Soil. Technical Gazzete, 14(1), 6675. https://doi.org/10.31803/tg-20190606115822

[25] Zhao, Y., Cao, P., Feng, D. C, \& Jing, R. X. (2012). Threepoint bending beam model simulates subbase fracture of semi-rigid pavement. Journal of China \& Foreign Highway, 32(5), 62-66. https://doi.org/10.14048/j.issn.1671-2579.2012.05.029

[26] Saride, S. \& Kumar, V. V. (2017). Influence of geosyntheticinterlayers on the performance of asphalt overlays on precracked pavements. Geotextiles and Geomembranes, 45(3), 184-196. https://doi.org/10.1016/j.geotexmem.2017.01.010

[27] Ghadimi, B., Nikraz, H., \& Rosano, M. (2016). Dynamic simulation of a flexible pavement layers considering shakedown effects and soil-asphalt interaction Transportation Geotechnics, 7, 40-58. https://doi.org/10.1016/j.trgeo.2016.04.003

[28] Xin, Q., Dou, Y., Zhang, J., \& Li, S. (2018). Deflection calculation of partially prestressed concrete beams under heavy duty. DYNA, 94(3), 301-307. https://doi.org/10.6036/8737

[29] Kovrov, A., Kovtunenko, A., \& Vysochan, N. (2017). Strain diagrams of cross-section of reinforced concrete bending elements. Technical Gazzete, 11(4), 175-181.

[30] Tomás-Espín, A. \& Sanchez-Olivares, G. (2018). Optimum reinforcement and sizing of concrete cross sections subjected to flexural and axial loading. DYNA, 93(5), 512-520. https://doi.org/10.6036/8676

\section{Contact information:}

Hongjun JING, PhD, Professor

(Corresponding author)

1) School of Architectural and Civil Engineering,

Xi'an University of Science and Technology, Shaanxi Province, China

2) Road Engineering Research Center of Xi'an University of Science and Technology, Shaanxi Province, China

Room 2009, No.58Yanta Road, Shaanxi Province, China

E-mail: jinghonhjun@xust.edu.cn

\section{Mingjie GOU, MS}

1) School of Architectural and Civil Engineering,

Xi'an University of Science and Technology, Shaanxi Province, China

2) Road Engineering Research Center of Xi'an University of Science and Technology, Shaanxi Province, China

Room 2009, No.58Yanta Road, Shaanxi Province, China

E-mail:787267175@qq.com

\section{Lichen SONG, MS}

1) School of Architectural and Civil Engineering,

Xi'an University of Science and Technology, Shaanxi Province, China

2) Road Engineering Research Center of Xi'an University of Science and Technology, Shaanxi Province, China

Room 2009, No.58Yanta Road, Shaanxi Province, China

E-mail: 1249138957@qq.com 